\title{
Data Governance in the Sustainable Smart City
}

\author{
Krassimira Paskaleva ${ }^{1, *}$, James Evans ${ }^{2}$, Christopher Martin ${ }^{3}$, Trond Linjordet ${ }^{4}$, Dujuan Yang ${ }^{5}$ \\ and Andrew Karvonen ${ }^{6}$ \\ 1 Manchester Institute of Innovation Research, Alliance Manchester Business School, \\ University of Manchester, Denmark Road Building, Manchester M13 9NG, UK \\ 2 Manchester Urban Institute, University of Manchester, Oxford Road, Manchester M13 9PL, UK; \\ James.Z.Evans@manchester.ac.uk \\ 3 Post-Doctoral Research Associate, Department of Geography, Durham University, \\ Lower Mountjoy South Road, Durham DH1 3LE, UK; christopher.j.martin@durham.ac.uk \\ 4 Centre for IP-based Service Innovation, Department of Electrical Engineering and Computer Science, \\ University of Stavanger, Stavanger P.O. Box 8600, Norway; trond.linjordet@uis.no \\ 5 Information Systems in the Built Environment Group, Department of the Built Environment, \\ Eindhoven University of Technology, 5600 MB Eindhoven, The Netherlands; D.Yang@tue.nl \\ 6 KTH Royal Institute of Technology, Urbana o Regionala Studier, Drottning Kristinas väg 30, \\ 10044 Stockholm, Sweden; apkar@kth.se \\ * Correspondence: k.paskaleva@manchester.ac.uk
}

Received: 23 July 2017; Accepted: 6 November 2017; Published: 15 November 2017

\begin{abstract}
The wisdom of 'smart' development increasingly shapes urban sustainability in Europe and beyond. Yet, the 'smart city' paradigm has been critiqued for favouring technological solutions and business interests over social inclusion and urban innovation. Despite the rhetoric of 'citizen-centred approaches' and 'user-generated data', the level of stakeholder engagement and public empowerment is still in question. It is unclear how smart city initiatives are developing common visions according to the principles of sustainable urban development. This paper examines how data governance in particular is framed in the new smart city agenda that is focused on sustainability. The challenges and opportunities of data governance in sustainability-driven smart city initiatives are articulated within a conceptual Framework on Sustainable Smart City Data Governance. Drawing on three cases from European countries and a stakeholder survey, the paper shows how governance of data can underpin urban smart and sustainable development solutions. The paper presents insights and lessons from this multi-case study, and discusses risks, challenges, and future research.
\end{abstract}

Keywords: data governance; sustainable smart city; initiatives; sustainability

\section{Introduction}

Smart solutions have a key role to play in making cities sustainable and resilient (e.g., [1-7]). A 'smart city', however, cannot only provide innovative solutions for urban infrastructure, better public services for the citizens and better use of urban resources but must also guide how people govern and make decisions so sustainable urban development can be ensured [8]. Through the use of digital technologies and urban data that are open to the public, more sustainable forms of governance are possible (e.g., $[9,10])$. Yet the changes in urban governance triggered by Information and Communication Technologies (ICT) pose new questions about the role and importance of data governance for achieving the goals of sustainable development. By increasingly involving urban actors in smart city initiatives, local government is expected to adapt and make effective use of these changes so smart solutions have long-term positive impacts for people and their city. However, demonstrating smart sustainability through the data that cities generate and use raises many governance questions $([6,7,10-12])$ : For example, 'How does the relationship between government and civil society change 
in the era of digital data?'; 'What is data governance in the context of a sustainable smart city?'; 'How can data governance be operationalised in smart city initiatives so meaningful and valuable data are created and utilized for the purpose of sustainable urban development?' Complementing general views of the smart city as a blend of institutions, processes, people, and technology, this paper elaborates on the role of data and data governance. We argue that data governance requires engaging with stakeholders in a collaborative process to generate and use the data necessary for developing smart solutions for sustainable urban development. While the debate about data governance in the smart city is growing, there are limited studies that deal with data governance in local-level sustainability initiatives (e.g., [6,11]). In this study, we presume that smart cities require sustainable development and identify the challenges and opportunities that local smart initiatives face in pursuing sustainability objectives.

This paper is inspired by works by Saujot and Erard [6], Goldsmith and Crawford [9] and Urban Transitions [7]; however, in the study we provide a connection between smart city data governance and sustainable urban development (e.g., $[13,14])$. First, we discuss the 'smart city' discourse and outline how sustainability has become increasingly fused with it, based on which we discuss data governance in the smart city and in local initiatives. The paper address two specific questions: First, 'What constitutes data governance in the sustainable smart city?' and second, 'What are the challenges and opportunities to data governance in sustainability-driven smart city initiatives?' These questions are answered empirically and critically through a multi-methods approach. This comprises a retrospective literature review to provide the conceptual framework for studying data governance in smart and sustainable city initiatives, and a stakeholder survey of professionals in three European cities. Since smart city governance is an evolving concept, the contribution to data governance research at the level of local initiatives—which make a city smarter (e.g., $[15,16]$ )—is an important topic. The current research is exploratory in nature; its main objective is to gather preliminary information and form insights that will help define key issues in the field and suggest hypotheses for future studies.

The empirical work is carried out in three case study cities in Europe-Manchester (United Kingdom), Eindhoven (The Netherlands), and Stavanger (Norway) — which form part of the Triangulum project (2014-2019). Triangulum is a $€ 25$ million Horizon 2020 project funded by the European Commission that aims to develop cutting-edge smart city solutions across the domains of energy, mobility, and ICT to underpin sustainable smart urban development [17]. With a reference to a Monitoring and Assessment Framework that was developed by the authors of this paper in a proceeding Triangulum study ([18] and findings of related research on 'smart sustainability' as a new urban fix [19], the current paper contributes a new understanding of data and smart city governance with regard to the sustainability of local initiatives (e.g., [15]). We analyse case study documents and qualitative data from the data governance survey administered to government officials and other actors who are responsible for the initiatives with respect to six key areas of Data Governance in a Sustainable Smart City Initiative: The project's context, data identification, data collection and generation, data sharing and management, data use and legacy. The insights and lessons learned from this multiple case study do not constitute a checklist, but can rather be used as guidelines when applying data governance in a local context. Results of the study can influence further development in the Triangulum projects as well as developments in three 'follower' cities, where replication of the solutions is to take place-Leipzig (Germany), Prague (Czech Republic), and Sabadell (Spain)—and beyond. The remainder of this paper is organised as follows: The next section provides an overview of the literature and the proposed conceptual approach to understanding and implementing data governance in smart city initiatives. The subsequent section describes the methodology, the case studies and Triangulum's Framework on Data Governance. Then the following section reports the findings from the analysis of the data. The final section addresses the limitations of the study and future research, and offers concluding remarks. 


\section{Theoretical Foundations}

In this section, the key concepts are embedded in their theoretical contexts. A discussion of the literature aims to help us understand sustainable development issues and the complexity of smart city data governance.

\subsection{Sustainable Smart Cities as a New Urban Policy Paradigm}

Over the last decade, the concept of the 'smart city' has evolved as a radical new approach to remedy urban problems and make urban development more sustainable. Many urban scholars and European Commission (EC) policy makers envision that 'smartness' will drive urban transformation, with smart cities becoming the engines of sustainable development $([2,20,21])$. To turn these transformative visions into reality, the EC has invested $€ 210$ million in so-called 'Lighthouse' initiatives, which seek to demonstrate, at scale, the benefits of digitally driven smart sustainable urban development [22]. It appears that the smart city agenda is being augmented and extended in present time in the domains of policy and emerging research by notions of sustainability. However, on what basis this augmentation takes place and where the evidence is for that basis is not clear. A question arises: 'Does a rhetorical commitment to sustainability mean that sustainability is actually being delivered?' Existing smart city research suggests not.

With the expansion of ICT in all spheres of life, the literature on the smart city has grown radically since the late 1990s. Starting from the original notion of 'smartness' in which ICT plays a key role in improving quality of life and achieving economic excellence in the city [23], the definitions of the smart city have mainly evolved along four key directions, representing the perspectives through which the concept has been studied: Technology, people, institutions, and processes [24]. Smart innovations—not necessarily based on ICT—-that utilize city resources and improve local everyday life are being reported to drive flagship projects in Europe and beyond. There is an unprecedented amount of literature on the smart city topic today, yet-as ambiguities remain-interest continues to grow. A number of comprehensive studies have recently attempted to explore its complex landscape (e.g., [5,16,21,25-27]). One common vision is emerging-that the smart city is a multi-dimensional and multi-layered concept that includes a wide range of elements. Thus, the majority of authors suggest, smart cities should be studied and analysed on the basis of multiple components, in their specific context.

Alongside these debates, recent discussion of the conceptual definition of smart city has also emphasized the relation of the smart city to sustainability. Proponents of this vision have argued that, contrary to what is usually perceived, the smart city paradigm does not only deal with technology but also with the socioeconomic and environmental issues of the city, as well as the increased amount of available data and the enormous potential of ICT applications. It was Hollands [28] who first called for a conceptualization of the idea of a smart city to include important aspects beyond technology. Nam and Pardo [5] went further and proposed that the smart city should no longer refer to the diffusion of ICT but should look at people and community needs, and therefore "smart cities should be sustainable, converging economic, social, and environmental goals." Thus, "... technology needs to be understood as a means to enable social, environmental, economic, and cultural progress in cities" [5]. In this context, achieving urban sustainability goals depends on the direct participation of local actors and stakeholders in the process of thinking, defining, planning, and executing social, technological, and urban transformations in smart cities [29]. In this way, integrated-social, economic, and environmental-meaning can be given to smart city solutions [30]. In the growing debate about the role of 'innovation' in the smart city, Anthopoulos and Reddick [24] also added that the innovative solutions that many cities seek today-not limited to but mainly based on the ICT-should aim to enhance local sustainability and the everyday life of citizens.

Yet, the transformative credentials of 'smartness' are relatively unknown and its environmental, economic, and social challenges remain little studied [19]. The emergence and contradictions of sustainable smart cities remain under-researched, and they are widely recognised as being in 
considerable need of further conceptual and empirical research [31]. The attempt by authors to wrap a pre-existing agenda of 'sustainability' inside the new agenda for 'smartness' is not yet supported by enough evidence that demonstrates that this position is plausible. As Komninos et al. [32] found, no smart city application or solution has yet fostered a truly radical change in city sustainability. Detailed documentation on the impact of smart city solutions for cities is also rare. The Amsterdam Smart City, for example, which is one of the best-known smart cities globally, aiming to enhance sustainability in the fields of living, working, mobility, and public space through a consortium of public and private organizations, is yet to show a real, measurable impact. Why, in the absence of this evidence, does the drive for 'smartness' continue then? Do its drivers lie in the delivery of sustainability? It is around this issue and the role of governance that the present research has evolved.

\subsection{Smart City Governance and the Role of Data}

In line with the growing debate about the role of people and communities in the smart city, studies have acknowledged the leading role of governance in attempting to make the city smarter and more sustainable (e.g., $[5,13,16,21,33,34])$. The governance domain has also emerged as critical to realising the broader objectives of smart urban transition (e.g., $[7,8,19,35,36])$. Despite the varied approaches, smart governance is considered core to smart cities and includes citizen participation in sustainable collaborative processes based on ICT ([14,35]). In this dynamic, stakeholder relations, the ability to cooperate, and the structure of the collaborations are defined as the key factors of success $([34,37,38])$; promoting data exchange and communication are important drivers [39]. Following Odendaal's approach to smart city governance and the ideas of sustainable and smart urban development from the previous discussion, the current research focuses on the role of data governance with the view that it is about the alignment of technological potential with urban governance strategies and processes to form a consistent sustainability approach to tackling urban problems collaboratively by stakeholders [40]. In essence, our working assumption is that the purpose of data governance is to create collaborative smart solutions for sustainable urban development [7]. The overriding hypothesis is that the smart city paradigm reframes governance as opportunities for stakeholders to engage in decision-making processes in the pursuit of a better life in the city [36]. In this context, smart city governance employs a citizen-centred view in which citizens and other stakeholders are treated as key assets for developing and implementing smart cities [41]. This implies that what makes smart governance work is governance capacity (e.g., finding human capacity and ability to engage, relational capacity (e.g., developing sustainable and trustworthy relationships and shared commitment), and organizational capacity (coordination, communication and integration) [42]. Despite the growing emphasis on the role of governance, however, the smart city paradigm surprisingly underestimates the complex governance dilemmas that emerge from the availability of 'big' and 'open' data in the smart city [43] and the 'data governance' construct remains a largely under-researched theme. Even more so, the potential of data governance dilemmas emerging from the smart cities narrative are yet to be given empirical attention.

\subsection{Towards Understanding Data Governance and Sustainable Smart City Initiatives}

It is obvious that all societal sectors are being affected by what is often called a 'data revolution', whether it is the economy, energy, mobility, health, well-being and environment, government, community and everyday life, consumption, or leisure. Within all such sectors, diverse sources are generating enormous amounts of data that are directed, automated, or volunteered $([3,31])$. Much of this 'big' data is also accessible to the public, thus 'open', and in that respect promoting transparency and data-empowering citizens, businesses and civil society [44]. In the context of urban government, such data pertain to all areas of life in the city-demographics, housing, traffic, pollution, crime, and health; essentially anything public authorities register and manage. The 'open data' agenda of the European Union advocates that data should be freely used, shared and built on by anyone, anywhere, for any purpose, to drive innovation and yield major social and economic benefits in 
the member states [12]. Although limited, there is evidence that the willingness of government and citizens to share and experiment with data for their own benefit is increasing. Moreover, $50 \%$ of European citizens in large cities are predicted to be sharing personal data with Smart City Programs by 2019; the Digital Customer Service of the European Union forecasts that through open data $20 \%$ of local government organizations in EU countries will generate revenue by 2020 [44]. However, to make these predictions into evidence of what is already occurring, it seems that studying the complexity of data in the smart city asks research to focus on the key concepts of urban governance (e.g., [43]).

As in the development of smart urban solutions, a variety of actors can be engaged in collecting, analysing, creating and presenting urban data, leading-again — to variable actor relations, in which citizens can participate in variable ways [45]. Our sustainability approach to the smart city emphasizes that data governance should be an inclusive and iterative process of data development by the stakeholders for the shared benefits of both people and city. This characterization implicitly builds upon the role of the data governance through stakeholder engagement and citizens' participation, for addressing specific social and urban outcomes, such as health, energy efficiency, mobility, and environment. Data governance can be considered at a high level of transformation as it requires transformations in internal and external relationships and structures in the smart city. However, considering that the smart city comprises various locally based initiatives, we also argue that these transformations in data governance have to occur at the level of smart city projects as well. Whereas until now the role of data governance mostly focused on the smart city level, the issues of data governance and its sustainability challenges emerge as a field requiring specific attention on a local level as well.

The governance agenda of local initiatives has been long established in the urban sustainable development domain. In studying governance in the smart city, Alawadhi et al. [5] too recognised the need to study participatory governance in local initiatives. Promoting collaboration in specific areas (inter-organizational, inter-sectoral, and government and other stakeholders) is held to be one of the important success factors for smart city initiatives $([5,38,39,46])$. Just recently, van Winden and van den Buuse [47] also found that overlooking the challenges to 'partnership governance' accounts for the "... lack of scaling of smart city projects, many of which fade out after the pilot stage and fail to generate scalable solutions that contribute to sustainable urban development". Yet, governance approaches are still not well integrated into smart city frameworks [19] and relatively little is known about the effectiveness of collaboration in sustainable smart city initiatives. Likewise, the ways that governance and new data sources such as social media, the Internet, and sensors are making cities smarter are also unexplored. The sustainability dimension of this dynamic is even less debated. At the same time, it is possible that through engagement with local communities and stakeholders, local smart initiatives can draw on the opportunities (and drawbacks) of new urban data, technologies and networks, with a particular focus on urban sustainable development. This means that governance is in effect the landscape for understanding and driving processes and activities in data-sensitive issues related to sustainability in the smart city.

Figure 1 illustrates the integrated nature of our research agenda of smart city governance. These cluster-transcending elements are especially important in developing more understanding about data-sensitive governance in smart cities as well.

The potential applications of data governance in the smart city can be significant. Through data governance, cities can tailor data to the specific needs of the stakeholders in important areas such as urban decision- and policy-making, service development or management. They can also realise their sustainable development goals in urban sectors (e.g., [4]). Opening local government data to the public can empower stakeholders and provide for more effective data use for everyone [48]. Giving access to open data that matters to citizens can also provide people with a citizen-specific and contextualised smart environment. The realisation of these potentials, however, poses questions about creating 'meaningful' data that account for the context and the objectives of the sustainable smart solutions [49]. Even so, harnessing data to improve urban sustainability is a big step cities are yet to 
take. As connectivity and collaboration are growing ever more, it seems important that smart cities and their citizens become more aware of the value and potentials that data governance has for sustainable urban development. Developing smart city projects that deliver services and infrastructure that meet sustainability objectives can help with studying this phenomenon.

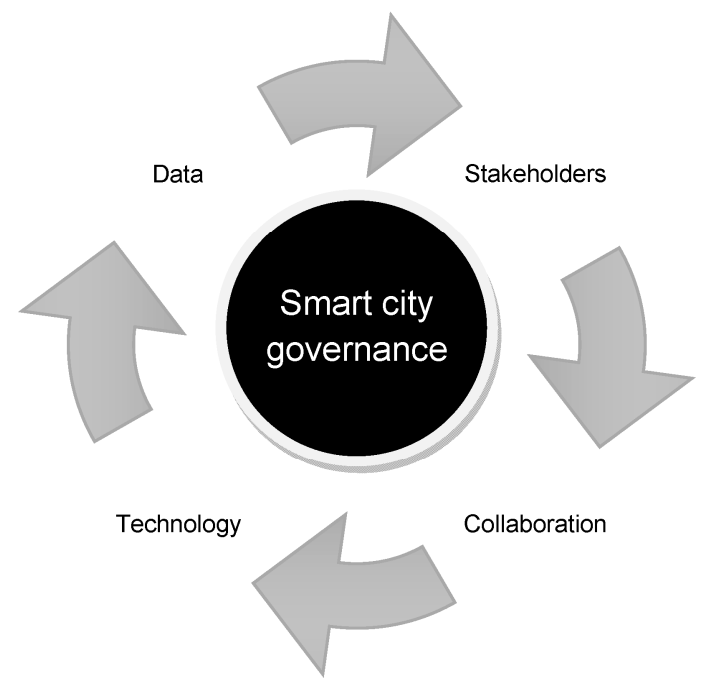

Figure 1. Key pillars of smart city governance.

\subsection{Operationalising Data Governance in Sustainable Smart City Initiatives}

In the search for what drives governance success in smart city initiatives, authors have drawn frameworks that explain differences in context, aims, and achievements. With regard to data, what appears important from the literature on data governance discussed earlier are the issues of meaningful data (or data relevancy), quality of data, as well as the challenges to collect and apply data, including the issue of data literacy for the citizenry of the smart city. Considering that smart city governance is based on stakeholders' sharing and aiming of common sustainability goals, the access to and legacy of data seem critical for the success of local initiatives beyond their lifetime. Generating data that reflect on the visions and aspirations of the stakeholders seems important too. In this context, collecting data that ensure an understanding of the impacts that smart city initiatives have on various aspects of a smart city-governance, people and communities, economy, natural environment, and built infrastructure (e.g., [16])—is another key factor. Finally, securing data that show how stakeholder relationships influence these factors as well as the different level of impacts collaboration has on the outcomes of the initiative and the broader urban sustainability agenda of a city are dimensions of data governance that deserve attention as well.

Following the preceding discussion, we can suggest that 'data governance in smart city initiatives' is about utilization of data and new technologies-the Internet, sensors, and social media-to identify, collect, generate, share and employ data developed for and by the citizens, urban governments, businesses and academia, to create smart and sustainable urban solutions in local areas and communities (e.g., [50]). Although there are a number of local initiatives—such as Greater London Authority's use of open data to stimulate sustainability [43] - little is known about their data governance challenges. To study the phenomena in sustainability-driven initiatives in Manchester, Eindhoven and Stavanger, this research brings forth some key dimensions of data governance in the smart city, identifies the conditions that shape them and underlines its contributions to sustainability (social, environmental and democratic). Specifically, we look at how smart initiatives-districts and experiments-are appearing in cities, and how these phenomena can reshape cities in their search for sustainability.

The study is carried out in close collaboration with officials from the Cities of Manchester, Eindhoven, and Stavanger, and respective their stakeholders, to ensure its value for the practitioners, 
citizens, and policy-makers. As we focus on actually existing examples of smart city initiatives, the findings of the study can appeal to both scholars and practitioners. The aim is to present the acquired insights in the form of research-based knowledge of governance and sustainable urban development, which can be utilised to enhance data governance in smart cities. As it was revealed, this knowledge is a dire need, since the alignment of smart governance with data governance and sustainable smart city strategies is a key challenge for our cities. Having established the conceptual foundations for our empirical research, we turn to exploring how data governance is being constructed within the Triangulum case cities. In doing so we focus on the main dimensions that construct data governance, and the sustainability pressures necessitating and shaping its presentation.

\section{Method}

We apply multiple case studies research to answer the 'what', 'how', and 'why' questions of the data governance phenomenon within the real-life context of the smart city. We use qualitative research methods in case studies not only to explore and describe the phenomenon-to capture the complexity of the smart city data governance and the contextual conditions of each local initiative-but to explain causal relationships and develop a theoretical hypothesis [51]. Following, we conduct a stakeholder survey to explore what drives or hampers data governance in local initiatives and the challenges posed by sustainability. Two types of data sources were used in the study-primary and secondary. Secondary data were mainly sourced from scientific publications and smart city research presented at top international conferences. Data gathered from various articles and books available in online libraries like Google Scholar, ScienceDirect, Scopus, IEEEXplore, and Triangulum's formal and informal documentation (project's description of work, study reports, working/journal papers, workshop minutes, and online group discussions) helped generate a smart city data governance conceptual framework. Primary data were gained through a self-administered stakeholder survey carried out in the three Triangulum smart city cases.

The research questions of the study and its conceptual approach guided the design of the survey questionnaire, composed of open-ended questions (see Appendix A). The qualitative methods are suitable for this study as they enable us to probe for more information and clarification of our research hypothesis [52]—-that sustainability shapes data governance in the smart city—drawing on not just the perceptions but also the experiences, opinions, and attitudes of the participants in real-life smart city initiatives. Survey questions are mostly open because they can increase the richness of answers and relationship mapping between the key dimensions of the conceptual approach employed. In addition, the research aimed to retrieve data from the perspectives of all stakeholders so governance issues could be tackled. The self-completed questionnaire is well suited for this research as it allows for a good rate of responses [53].

A number of limitations relate to the research design. As the investigated problems are in a preliminary stage and large sets of data are difficult to collect, exploratory research is applied based on a conceptual framework. The findings of this study are therefore restricted to the available sources and early stages of theoretical and empirical development in the domain. The discussion is based on limited empirical evidence and is primarily descriptive, but the conceptual framework and Triangulum's integrated approach to data governance provide for stronger theoretical resonance to the empirical results. The self-administered questionnaire is exploratory in nature and is used as a starting point for other methodologies to further explore the research questions and collect more comprehensive data in a subsequent stage. Furthermore, the study aims to yield findings with research and practical implications based on existing project and pilot cases that may have influenced the design, application, and findings. Potential flaws are mitigated by the long-term involvement of the two lead authors and members of the Manchester evaluation team in projects and research across the fields of smart cities, governance and sustainability. Finally, as the survey administration was placed in the hands of the managers of the pilot projects, and due to organisational issues, it could have not been 
handled collectively by all actors, as was the intention. Yet, the diverse expertise of the respondents is a positive factor, as it reflects the views of the different stakeholders in the smart city.

\subsection{Triangulum's Specific Approach and Case Studies}

The Triangulum international project aims to test and demonstrate the benefits of integrating smart technologies across urban energy, mobility, and ICT sectors in three 'Lighthouse cities' - Eindhoven, Manchester and Stavanger-each of which is seeking to position itself as a leader in smart and sustainable urban development. All three cities have shown a strong political commitment to offer their urban space as a living lab for innovative, co-created, smart city solutions. Manchester, for example, seeks to reduce air pollution, traffic congestion, and energy costs while fostering economic growth, developing a digital infrastructure, and fostering citizen engagement with digital infrastructure. Eindhoven has the ambition to be energy-neutral by 2045 to contribute to a drastic reduction of the overall $\mathrm{CO}_{2}$ emissions and sustain human life in the city. With this target, Eindhoven seeks to engage with urban stakeholders in its policy and decision-making processes in all spheres of urban life that influence the process. Stavanger holds the title of the 'European Capital of Energy'. With a long tradition of citizen involvement and a well-developed ICT cluster, the city wishes to become one of Europe's foremost sustainable cities by promoting integrated solutions across ICT, energy, and mobility.

Triangulum also seeks to replicate successfully demonstrated solutions or activities in three 'follower cities' - Prague, Sabadell and Leipzig — as well as elsewhere through a common standardised approach of smart and sustainable urban development. The outcomes that Triangulum seeks to deliver by 2020 are: A significant reduction of energy demand and local GHG emissions whilst at the same time enhancing quality of life, delivering efficient and clean mobility to residents and local workers, and providing the basis for economic growth and development in the participating cities [18]. The consortium seeking to realise these sustainability goals consists of municipal governments, regional development agencies, built environment consultancies, construction companies, digital economy enterprises, non-for-profit organisations, and universities in the six countries. As one of the first round of Lighthouse initiatives that started early in 2015 and are expected to demonstrate sustainable smart solutions in 'module projects' across three European cities, Triangulum offers opportunities to study data governance in real-life local initiatives in greater detail.

Building on the concept of 'urban living labs', where collaborative innovations occur, Triangulum promotes a form of smart city development that frames the city as a series of module projects. The vision is that it is at this project level that impacts are generated and thus causal relations between interventions and resulting impacts can be established and verified [54]. This focus is critical as stakeholders together identify the benefits of the solutions and link them to indicators and metrics, thus creating individual project-based assessment opportunities. The projects represent the building blocks of Triangulum. They are the scale at which consortium partners seek to enact smart cities and the level at which replication can be achieved through procurement and decision-making processes. The project scale is also considered the most consistent scale for measurement and comparison, because cities differ widely in their smart city context.

Triangulum's high-level activities are primarily framed by consortium members as the development of sustainable smart urban districts - two districts in each of Eindhoven and Stavanger, and one district in Manchester. These sustainable smart districts are being understood as spatial constructs, but also as discursive constructs in that they are both actual places and visions of what these places should become in context of the rhetoric that surrounds Triangulum. The process of realising these visions is based on collaborative creation of data and integrated communications in old or new spatial districts to develop smart city solutions that meet the needs of sustainable development. In contrast to previous EU projects, Triangulum does not focus on a broader public policy agenda of smart city development, but rather works from the micro-scale up to the city level and in reverse in order to determine how 
module projects fit together to achieve smartness, sustainability, and overall contribute in the long term to the creation of a smart sustainable city [18].

The districts vary in their characteristics and the key objectives pursued by those who govern them: Residential (Hillevåg, Stavanger and Eckart-Vaartbroek, Eindhoven), urban (The Corridor, Manchester and City Centre, Stavanger), and formerly industrial (Strijp-S, Eindhoven) districts are sites for Triangulum's sustainable smart urban solutions. Some districts have been established for almost a decade (The Corridor, Manchester), while others were newly created to provide a vehicle for the Triangulum interventions (the two Stavanger districts). Across these districts, forms of urban governance that Triangulum supports and reinforces are in general entrepreneurial in their pursuit of economic growth and competiveness goals, alongside a desire to address longstanding social and environmental challenges arising from the ongoing growth of economic activity. In terms of the former, competiveness goals are particularly prominent in the Corridor district (to become a world-class innovation district) and the Strijp-S district (to develop an international reputation as a place to live and for new start-ups to grow). Triangulum's activities are also strongly orientated towards addressing a specific and longstanding environmental challenge, the reduction of carbon emissions to sustainable levels. Challenges in all three project areas—environment, mobility, and ICT—are being addressed in all five districts and smart data governance practices are being constructed simultaneously in all districts.

\subsection{Research Design}

Triangulum adopts a 'quadruple helix' approach to collaboration-based on partnerships between public sector, private sector, univer sities, and citizens. The cross-sector collaborations that have been developed to date involve private sector companies who deploy smart technologies in collaboration with a diverse range of local infrastructure owners including housing associations, municipal governments, universities, and private homeowners. The extent to which citizens are actually engaged in Triangulum varies from district to district and from project to project:

- In the Corridor district (Manchester), the focus of low-carbon technology deployment on the university campuses has limited the possibilities for residents of the wider city to shape modules and derive benefits from them, which raises questions about how the benefits to them will, in practice, be verified and measured.

- In the Eckart-Vaartbroek district (Eindhoven), low-carbon technologies are being deployed in low income households proving them with the opportunity to act as co-producers of renovation process and benefit directly from Triangulum's investment.

- In the city centre (Stavanger) low-carbon technologies are being deployed to provide public transport services and reduce energy consumption in selected domestic households, offering opportunities for some citizens to directly participate in Triangulum's activities.

Triangulum pursues a strong governance approach to data in its initiatives, based on six main principles:

1. In Triangulum, smart cities are to be co-created with the citizens. Stakeholders are involved in the process of development and improvement of smart city solutions, to ensure that solutions are demand-driven and contribute towards real-life improvement of cities.

2. Triangulum seeks to capture the myriad ways in which the smart city initiatives are embedded in the city to develop an understanding of their context, and overall or total benefit.

3. Triangulum adopts a comprehensive monitoring and assessment approach with a focus on the scale of demonstration initiatives-in districts or local areas-so causal relations between interventions and resulting impacts can be established. Impacts are being measured context-specifically in each initiative in terms of its own objectives. Both governance and sustainability-relevant issues are being taken into an account. The University of Manchester is 
leading the monitoring and impact assessment activities, together with academic and government institutions from the Lighthouse cities.

4. A highly collaborative approach to data development is adopted, driven by and supporting the needs and capacities of local stakeholders. It falls into both the spatial and digital landscapes in sharing a desire to make urban development and infrastructure more sustainable, based on governance structures and the creation of data. Data are being made openly available, enabling key actors (including project partners in Lighthouse and follower cities) and external users to engage with, use and create value from Triangulum datasets. In addition to collecting and analysing a range of quantitative data, work focuses on the ability of cities to provide and use different forms of data at different spatial and temporal resolutions.

5. A bottom-up approach is adopted towards data development in the project's initiatives. Stakeholders are involved from the onset of the creation of the smart city solution, from setting up its objectives and parameters, to the desired impacts and the data and metrics its realization requires. Having real smart city projects to study and assess data governance is a unique feature that Triangulum offers.

6. Triangulum partners and urban stakeholders are also learning partners, so preferred metrics and datasets are determined by consulting extensively with all parties so appropriate data are obtained on time. The approach recognises that the understanding of smart data and available datasets will evolve over time as activities mature. In this way, Triangulum stakeholders are encouraged to prioritise data governance-sensitive issues and develop collaboratively the data that the initiative needs.

During the first 12 months of the project, in the process of developing Triangulum's Impacts Assessment and Monitoring Framework, a set of structured reflections on the process of identifying and securing data with the partners in the module projects were collected from the cities [54]. These reflections highlighted some of the key areas that data governance must address. It also transpired that data should be relevant to the specific context of the module project. This emphasized the need to understand the specific conditions in each initiative as regards its capacities to deliver the desired impacts and the metrics and data necessary to verify them, before each module commences. Thus, at a very early stage it was attempted to understand what stakeholders want and are able to measure and, as the impacts of the initiatives become apparent, what is most important to measure. To contextualize the data-sensitive issues, a stakeholder survey was carried out.

\subsection{Data Governance Survey}

Development of the survey, over the autumn of 2016, was led by researchers at the University of Manchester. The survey was designed to address issues associated with data governance within, and related to, Triangulum. Specifically, data created by Triangulum module projects and data used to assess their impacts, including data from city stakeholders outside the project, were the focus. Five specific objectives were set up by the survey:

- Capture insight from the ongoing discussions within the project relating to data generation, collection, management, sharing, and use; and make some tentative recommendations.

- Provide a preliminary understanding of the highly collaborative approach to monitoring and data collection that is driven by and supports the needs and capacities of local partners.

- Identify the key challenges for the Lighthouse cities in terms of data monitoring during and after the project ends.

- Support efforts to create sustainable processes and structures of data development during and beyond the lifetime of the Triangulum project.

- Shed light on the key barriers to a data-driven sustainable smart city. 
The conceptual framework proposed below (Figure 2) visualizes the main pillars of Data Governance in Smart City Initiatives that derive from both the literature review in the current study and Triangulum's activities.

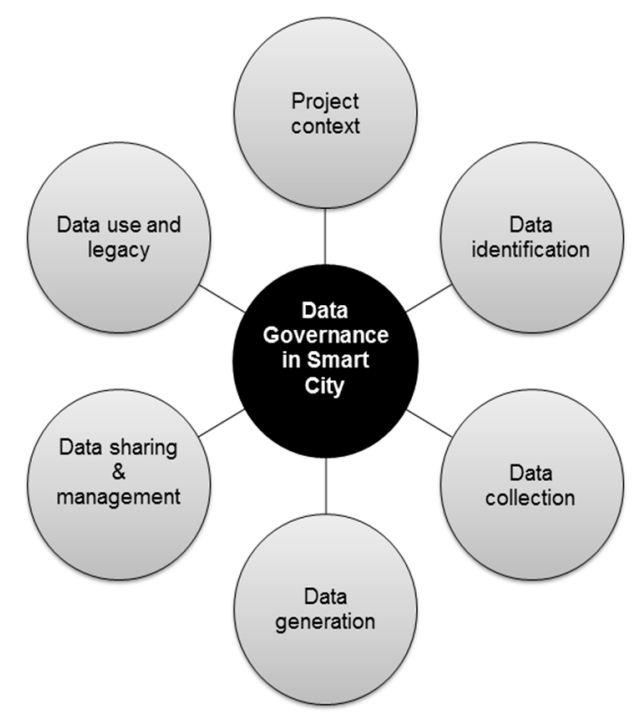

Figure 2. Key pillars of data governance in smart city initiatives.

The above diagram includes three key dimensions—-data collection, use, and management—identified in the prior studies of data in smart cities (see Section 2.3). Additional dimensions-project context, data identification, data generation, data sharing, and legacy of data-identified by the current study are added. These dimensions are categorised into six clusters in a sequential structure. The Data Governance Survey focused on the key decision domains of data governance that were identified by the case studies in the initial baseline stage. These are the following:

Data collection and generation. Questions in this section of the survey focused on the technical, policy, organisational, and regulatory enablers and barriers to collecting and generating data within the Triangulum project, and how partners had collaborated in the process.

Data management and sharing. Questions in this section of the survey focused on: The technical, policy, organisational, and regulatory barriers to sharing data generated within the Triangulum project; how data are managed within a pilot project; and, if novel approaches to data management are being developed. It is important to say here that in the current study, based on Weill and Ross [55] and Kharti and Brown [56], we differentiate between governance and data management as follows: Governance is about the decision that has to be made to ensure effective data management and 'who' makes the decisions 'how'; management involves implementing the decisions, including determining the actual metrics employed; in our case it refers to planning, development, implementation, and administration of the systems for the acquisition, storage, security, retrieval, dissemination, archiving, and disposal of data [57]. Here, we focus on the former.

Data use. Questions in this section of the survey focused on how members of the Triangulum consortium expect the data generated to be valuable to citizens, businesses, and municipal authorities and other public bodies.

Legacy issues. Questions in this section of the survey focused on which aspects of data collection, storage, or provision will or should outlast Triangulum, and the barriers to long-term data collection and provision.

Data development and project working. Questions in this final section of the survey focused on the effectiveness of adopting a collaborative approach to data collection and project working. The survey was conducted during February 2017. For its implementation, the Triangulum Evaluation Team focused on identifying partners in the project consortium who were collaborating on impact 
assessment and monitoring activities, as well as activities relating to the generation, collection, and sharing of Triangulum data in the smart city initiatives. Researchers in Manchester, Eindhoven, and Stavanger identified potential survey participants to target within their respective cities. As a result, a total of 18 potential survey participants were identified (10 in Manchester, four in Eindhoven, and four in Stavanger). An invitation to participate in the survey was circulated by email to these 18 partners, and survey responses were received over a two-week period (8-22 February 2017). Throughout this period, email reminders were sent out to all potential participants, and targeted follow-ups were conducted where few responses had been received from partners in a specific Lighthouse city. In total nine survey responses were received (four from Manchester, three from Eindhoven and two from Stavanger). Analysis and interpretation of the survey responses was conducted by the Triangulum Evaluation Team.

\section{Findings from the Analysis}

This section reports the results from the survey with key data stakeholders from the three case cities. Insights presented below relate to each of the five key dimensions covered in the survey.

\subsection{Data Collection and Generation}

\subsubsection{Collaborating in Data Collection}

The survey responses indicate collaborative work is taking place during data collection within and beyond the consortium, and between public and private sector actors, in each of the three Lighthouse cities. In Eindhoven and Stavanger data created by citizens are being collected. Responses to the question relating to the benefits and impacts of adopting a collaborative approach to data collection indicate the question was not sufficiently understandable to survey participants. Hence, this remains a topic to follow up in future Triangulum research.

\subsubsection{Barriers to Data Collection}

The survey participants identified a range of technical barriers to data collection including: A lack of historic data; challenges managing the large volume of data generated; lack of interoperability between devices and technologies; lack of standardisation of data formats; and, technical challenges ensuring data security and integrity. No consensus emerged over which barrier was the most prominent or widely experienced, and hence it appears likely that technical barriers are dependent on the specifics of the socio-technical configuration of each of the modules. There was a stronger consensus around the primary policy, organisational, and regulatory barriers experienced, with survey participants from each of the Lighthouse cities highlighting privacy and associated ethical concerns as barriers to data collection. In Manchester organisational challenges, in the form of the limited participation of data owners outside the consortium, were also noted.

\subsection{Data Management and Sharing}

\subsubsection{Data Management Practices}

Within and across each of the Lighthouse cities survey participants held differing perspectives on the question of who is responsible for facilitating, controlling, managing, and curating Triangulum data. This suggests that further work is required to communicate the data management principles set out in Triangulum and their governance perspectives. Interestingly, the University within each Lighthouse city was identified as a key actor with responsibility for data management, while a number of responses named a single person as responsible for data management, potentially highlighting a lack of resilience within the project to loss of key staff members. There were mixed opinions on the question of whether or not innovative approaches to data management and sharing were being adopted within Triangulum. At least one survey participant from each city thought not. However, other survey 
participants identified innovative approaches in the form of: Development of the Eindhoven data platform; the accelerated take up of technologies for making use of data created by electric vehicles in Manchester; and opening up new discussions around data management as a prerequisite to adopting new and innovative approaches to data governance.

\subsubsection{Barriers to Data Sharing}

The survey participants identified similar barriers to data sharing, to those barriers to data collection discussed above, suggesting that drawing a distinction between barriers to data collection and sharing in practice is challenging or not particularly meaningful. Specific technical barriers were noted, including: Challenges integrating data from multiple sources within single data platform; a focus on static (rather than real-time) data in Eindhoven, and challenges in redeveloping an existing platform that was originally intended for university staff and students to allow access to data by the general public (Manchester). In terms of policy, organisational, and regulatory barriers, privacy was frequently mentioned alongside concerns about data protection.

\subsection{Data Use}

The survey participants held high expectations that the data generated within Triangulum will be valuable to citizens, businesses, and municipal authorities and other public bodies. Eight out of nine survey participants believe it is likely or very likely that the data will be valuable to citizens. This value is expected to be realised as open access to data raises public awareness, and personal data leads to behaviour change (particularly in energy consumption and environmental issues). Eight out of nine survey participants also believe it is likely or very likely that the data will be valuable to businesses, in large part because the Triangulum project is orientated to generating and sharing data that could enable new business models and be commercially exploited. However, a note of caution was sounded by one survey participant, who noted that it is difficult to predict whether data made openly available to businesses will be of value as this 'comes down to the creativity of companies and developers'. All nine survey participants thought it is likely or very likely that the data will be valuable to municipal authorities and other public bodies. In particular, these expectations are based on the potential of the data to be used in city management and data-driven policy making (including environmental policy related to energy consumption and air quality).

\subsection{Legacy Issues}

A range of perspectives on which aspects of data collection, storage, or provision will or should outlast the Triangulum project was evident from the responses to the survey, suggesting that there is a lack of clarity and formalisation around sustaining the Triangulum data ecosystem beyond the end of the project. However, some insights can be gained from the survey responses. In particular, three participants expected data that have a clearly defined role to play in a partner organisation (e.g., data from building energy management systems) will continue to be collected. Interestingly, one survey response suggested that the organisational learning relating to data collection, storage, or provision would be sustained beyond the Triangulum project, rather than the data itself. Again, there were differing perspectives on which aspects of data collection, storage, or provision should be sustained. A key theme of the survey responses was that data relating to the impacts of modules-including use of modules, economic, and environmental benefits realised-should be collected and stored and shared beyond the end of the Triangulum project. The Triangulum Data Management Plan identifies the key principles for data archiving and preservation until the end of the project, but storage of data beyond the Triangulum project period is to be undertaken on an ad hoc basis, with considerations given to ongoing use of data by smart city service providers, including municipalities, other partners, and third-party businesses (for example, smart city service technology start-ups). Also, research relevance will inform decisions to retain data subsets. In practice this may mean that the majority or all of 
the data collected will be maintained and curated indefinitely, but a key task for the following stages of the project will be to manage and support this process within the Lighthouse cities.

\section{Barriers to Long-Term Data Collection and Provision}

The primary barrier identified in survey responses to long-term data collection and provision was lack of clarity around how this might be funded. The response highlighted that sustaining data collection and provision would require funding for: Staff time to maintain data platforms and perform manual data collection tasks; and, to maintain and develop an appropriate technological infrastructure. In Stavanger, a further barrier was identified in the form of the contracts between consortium partners and households participating in data collection ending at the end of the Triangulum project.

\subsection{Data Development and Project Working}

This section of the survey posed the questions ‘Has the collaborative process of data collection helped develop the scope and goals of the modules? If so, how?' Although three survey participants observed no evidence of this collaborative process, other survey respondents found that this collaborative process had helped with selection of technologies and approaches to data collection. Two responses highlight the central role played by universities; for example-'I believe that, by not having commercial interests in the data collected (or to be collected), the universities could safely play the role of coordinators and mediators in this process'. Other responses suggested that there remains the potential for closer collaboration between researchers and the organisations developing and deploying smart city modules.

\section{Concluding Remarks and Future Research}

The current study was driven by two research questions: 'What constitutes data governance in the smart city?' and 'What are the challenges and opportunities for data governance in sustainability-driven smart city initiatives?' An analysis of the literature showed that in the current drive towards smart and sustainable cities, 'smartness' is becoming a vehicle for the delivery of sustainable development agendas. In this context, sustainable development 'governance' becomes a main component of the sustainable smart city. The paper addresses the existing research gap concerning the ways in which smart cities are being deployed to deliver sustainable cities from the point of view of data governance.

The key findings of the paper reveal that smart city initiatives seeking to deliver sustainable urban development require engagement with stakeholders to collaboratively identify, collect, generate, and use data. Thus, sustainability shapes a more collaborative approach to data governance in the smart city that addresses broader calls to make smart data governance more responsive and collaborative. Each smart city comprises of local initiatives occurring in multi-level governance settings, but this study suggests that data governance is best operationalised at the level of each initiative-in urban districts or local areas-to ensure that all necessary data can be identified and provided in a meaningful format and timely fashion. Data development relies upon the mandates of all stakeholders, but government plays a key role in sharing data more broadly. Sharing data supports decision-making processes and stakeholder relationships that can shape the design and development of future smart and sustainable city initiatives.

The research presents the findings from the case studies and survey analysis with government officials and managers from three Triangulum cities, with reference to a Framework on Data Governance in the Sustainable Smart City. Given the cross-sector/actor and citizens-centred challenges, stakeholder engagement constraints represent key challenges to data governance in smart city initiatives. Yet, there is evidence that data governance can change data generation, collection, and use culture in the smart city. In smart city initiatives, participants can benefit not just from open access to data but from using it in ways that people and cities need. They can also add their own data so the desired impacts of the solution are reached. This way data governance raises stakeholders' awareness about the smart city and sustainability. It also facilitates collaborative learning, which may 
lead to behaviour change (particularly in energy consumption and sustainable transport). The nature of the stakeholder collaborations also raises questions around the extent to which smart data governance is understood by local populations.

The insights from the structured reflections and survey highlight key opportunities and challenges faced in smart city data governance. One such observation is that governance structures should be embedded in all key stages of data governance-from the identification and collection, generation and curation, to the use and management of the data as well as in securing its long-term legacy. A Data Governance Management Plan should identify the key principles for data archiving and preservation, not only to the end of the initiative but beyond its lifetime, with considerations given to on-going use of data by smart city service providers, including municipalities, other partners, and third party businesses. Data relating to the impacts of the initiative-including use of economic, social, and environmental benefits realised-should be collected, stored, and shared in the long term. Organisational and regulatory barriers relating to privacy are the most obvious challenges, alongside concerns of data protection and management. In terms of opportunities, it becomes clear that data are of use to citizens and cities, and it is very likely that the data will be valuable to businesses as well, which could enable new collaborative models and solutions to be commercially exploited.

It should be noted that this study presents a first analysis of data governance in smart city initiatives, and as such represents exploratory research. This exploratory research has helped us to gain insights and experience in formulating a relevant hypothesis for data governance in the smart city that is driven by the goals of sustainable development. In particular, it has been shown that governance of data in smart sustainable initiatives involves a set of six key data decision domains bundled in an iterative and sustainable collaborative process. By operationalizing the locus of data governance for each decision domain, the proposed Data Governance Framework can be used by practitioners to design their data governance activities.

The conceptual framework developed is preliminary. More definite investigations are necessary to consolidate the initial findings. The qualitative research applied is mainly descriptive in nature, so our intention is to follow-up with examinations of why the observations exist and what the implications of the findings are for further advances in the field. The knowledge gap derived from the exploratory research should be further addressed and discussed through in-depth interviews, focus groups, and/or quantitate studies. The self-administered questionnaire can serve as a starting point for other methodologies, so in addition to the indication as to the 'what', 'why', 'how', and 'when' sustainable smart city governance occurs, other issues such as 'where', 'how much', or 'how often' can be revealed. As only a limited number of experts were involved in the research, future research could involve more experts from all sectors of the smart city. This paper has highlighted the ways in which sustainable urban development is changing the ways in which local governments and other stakeholders can make use of data governance in their smart city initiatives. Future studies should focus on other cases in fine detail, in order to develop guidelines for data governance in a local context. Extending the scope of cases and practices around the world will advance this complex field.

Acknowledgments: This study was supported by a grant from the European Union's Horizon 2020 Programme for Research and Innovation under grant agreement No. 646578. The authors wish to acknowledge the valuable help and support from all members of the Triangulum Project team. The views and conclusions expressed in this paper are those of the authors and do not necessarily reflect the views of the partners or home institutions.

Author Contributions: K.P. and J.E. conceived of the presented idea. K.P. developed the theory and the conceptual model. J.E. verified the analytical approach and methods. C.M. constructed the survey questionnaire and conducted initial analysis of the results. All authors contributed to the design of the survey and interpretation of the results. J.E. finalised the empirical findings. K.P. developed the concluding remarks. All authors provided critical feedback and helped shape the research, analysis, and manuscript.

Conflicts of Interest: The authors declare no conflicts of interest. 


\section{Appendix A}

\section{Triangulum Data Generation and Collection}

Survey Questionnaire

\section{Name:}

Job title:

Role(s) in Triangulum:

\section{Data identification, collection and generation}

1.1 To what extent have module partners, policy makers, users, and the public been included in the collection of Triangulum data? (Please include names of participating partners/actors.)

1.2 What are the main technical barriers to collecting data created by Triangulum activities in your city?

1.3 What are the main policy, organisational, and regulatory barriers to collecting the data created by Triangulum activities in your city?

1.4 How has the collaborative approach of working with partner organisations impacted on the data that will be collected? (For example, will more datasets be created/made available? Does it relate to a greater range of impacts? Will it be of more use to partners/users beyond Triangulum?)

\section{Data sharing}

2.1 What are the main technical barriers to sharing data created by Triangulum activities in your city?

2.2 What are the main policy, organisational, and regulatory barriers to sharing the data created by Triangulum activities in your city?

2.3 Has Triangulum driven new approaches to data collection, stewardship, and open data?

2.4 Who is responsible for facilitating, controlling, managing, and curating Triangulum data?

\section{Data use}

3.1 Who is responsible for the provision of open data in standardized, easy-to-use formats for sharing with partners and city stakeholders?

3.2 How likely is it that data produced by Triangulum activities in your city will be valuable to citizens? Delete as appropriate: very likely/likely/unlikely/very unlikely/unsure Why is this?

3.3 How likely is it that data produced by Triangulum activities in your city will be valuable to businesses? Delete as appropriate: very likely/likely/unlikely/very unlikely/unsure Why is this?

3.4 How likely is it that data produced by Triangulum activities in your city will be valuable to municipal authorities and other public bodies?

Delete as appropriate: very likely/likely/unlikely/very unlikely/unsure Why is this?

\section{Legacy issues}

4.1 Will any aspects of data collection, storage, or provision outlast Triangulum?

4.2 What are the most important impacts that should be monitored beyond the lifetime of the project?

4.3 What are the main barriers to ensuring long-term data collection and provision? How can they be overcome? 


\section{Data development and project working}

5.1 Has the collaborative process of data collection helped develop the scope and goals of the modules? If so, how?

5.2 How has the process of data collection impacted upon working across organisations?

5.3 How has the coordinating role played by local universities impacted this process?

\section{References and Notes}

1. Baron, M. Do we need smart cities for resilience? J. Econ. Manag. 2012, 10, 32-46.

2. Bătăgan, L. Smart cities and sustainability models. Inf. Econ. 2011, 15, 80-87.

3. Batty, M. Big data, smart cities and city planning. Dialogues Hum. Geogr. 2013, 3, 274-279. [CrossRef]

4. Kharrazi, A.; Qin, H.; Zhang, Y. Urban Big Data and Sustainable Development Goals: Challenges and Opportunities. Sustainability 2016, 8, 1293. [CrossRef]

5. Nam, T.; Pardo, T. Conceptualizing smart city with dimensions of technology, people and institutions. In Proceedings of the 12th Annual Digital Government Research Conference, College Park, MD, USA, 12-15 June 2011; pp. 282-291.

6. Saujot, M.; Erard, T. Smart City Innovations for Sustainable Cities? Analysis Based on Data Challenges; Working Papers No. 02/15; IDDRI: Paris, France, 2015.

7. Urban Transformations n.d. Smart Governance of Sustainable Cities, Oxford University Network. Available online: http:/ / www.urbantransformations.ox.ac.uk/project/smart-governance-of-sustainablecities-smartgov / (accessed on 15 June 2017).

8. Ludlow, D. Shaping Common Ground in Urban Sustainability? Smart City Governance-Common Ground for Integrated Urban Management. 2016. Available online: http://jpi-urbaneurope.eu/app/uploads/2017/ 04/Ludlow_Shaping_common_ground_in_urban_sustainability_Smart_city_governance.pdf (accessed on 12 May 2017).

9. Goldsmith, S.; Crawford, S. The Responsive City: Engaging Communities through Data-Smart Governance; Jossey-Bass: San Francisco, CA, USA, 2014.

10. European Commission. Open Data Governance. 2015. Available online: https://eu-smartcities.eu/priorityareas/open-data-governance (accessed on 5 May 2017).

11. Van der Meulen, R. Developing Open-Data Governance in Smart Cities: The Democratization of Data in Cities Will Require Robust Governance Platforms. 2016. Available online: http:/ /www.gartner.com/ smarterwithgartner/developing-open-data-governance-in-smart-cities/ (accessed on 7 June 2017).

12. The Open Knowledge Foundation. Defining Open Data. 2013. Available online: http://blog.okfn.org/2013/ 10/03/defining-open-data/3 (accessed on 12 June 2016).

13. Caragliu, A.; Del Bo, C.; Nijkamp, P. Smart cities in Europe. J. Urban Technol. 2011, 18, 65-82. [CrossRef]

14. Giffinger, R.; Gudrun, H. Smart cities ranking: An effective instrument for the positioning of cities? Arch. City Environ. 2010, 4, 7-25.

15. Alawadhi, S.; Aldama-Nalda, A.; Chourabi, H.; Gil-Garcia, J.R.; Leung, S.; Mellouli, S.; Nam, T.; Pardo, T.A.; Scholl, H.J.; Walker, S.; et al. Building Understanding of Smart City Initiatives. In Electronic Government. EGOV 2012; Lecture Notes in Computer Science; Scholl, H.J., Janssen, M., Wimmer, M.A., Moe, C.E., Flak, L.S., Eds.; Springer: Berlin/Heidelberg, Germany, 2012; Volume 7443.

16. Chourabi, H.; Nam, T.; Walker, S.; Gil-Garcia, J.R.; Mellouli, S.; Nahon, K.; Pardo, T.A.; Scholl, H.J. Understanding smart city initiatives: An integrative and comprehensive theoretical framework. In Proceedings of the 45th Hawaii International Conference on System Sciences, Maui, HI, USA, 4-7 January 2012; pp. 2289-2297.

17. Triangulum: The Three Point Smart City Project: Demonstrate, Disseminate, Replicate 2017. EU H2020 Lighthouse Project, Smart Cities and Communities Programme. Available online: http:/ / triangulum-project. eu/ (accessed on 16 April 2017).

18. Evans, J.; Martin, C.J.; Yang, D.; Linjordet, T.; Karvonen, A.; Paskaleva, K.; Seehus, G.; De Vries, B.; Von Radecki, A.; Schmidt, A. Triangulum project: Impact Assessment and Monitoring Baseline Report (Deliverable 2.3). Available upon request from authors. 2016. 
19. Martin, C.E.; Evans, J.; Paskaleva, K.; Karvonen, A.; Yang, J.; Linjordet, T. Smart-sustainability: A new urban fix? Int. J. Urban Reg. Res. 2017. under review.

20. European Commission. The Basque Declaration: New Pathways for European Cities and Towns to Create Productive, Sustainable and Resilient Cities. 2016. Available online: http://www.sustainablecities.eu/ endorse-the-basque-declaration (accessed on 2 April 2016).

21. Gil-Garcia, R.J.; Pardo, T.; Nam, T. (Eds.) Smarter as the New Urban Agenda: A Comprehensive View of the 21st Century City; Springer: Berlin, Germany, 2016.

22. European Innovation Partnership on Smart Cities and Communities. Citizen Manifesto. 2015. Available online: https: / / eu-smartcities.eu/content/inclusive-smart-cities-european-manifesto-citizen-engagement (accessed on 10 June 2016).

23. Mahizhnan, A. Smart cities. Cities 1999, 16, 13-18. [CrossRef]

24. Anthopoulos, L. Understanding the smart city domain: A literature review. In Transforming City Governments for Successful Smart Cities; Bolívar, A.M.P., Ed.; Springer: Berlin, Germany, 2015.

25. Albino, V.; Berardi, U.; Dangelico, R.M. Smart cities: Definitions, dimensions, performance, and initiatives. J. Urban Technol. 2015, 22, 3-21. [CrossRef]

26. Mora, L.; Bolici, R.; Deakin, M. The first two decades of smart-city research: A bibliometric analysis. J. Urban Technol. 2017, 24, 1-25. [CrossRef]

27. Ojo, A.; Dzhusupova, Z.; Curry, E. Exploring the nature of the smart cities research landscape. In Smarter as the New Urban Agenda: A Comprehensive View of the 21st Century City; Springer: Berlin, Germany, 2015; pp. 23-47.

28. Hollands, R. Will the real smart city please stand up? City 2008, 12, 303-320. [CrossRef]

29. Prado, A.L.; Da Costa, E.; Furlani, T.; Yigitcanlar, T. Smartness that matters: Towards a comprehensive and human-centred characterisation of smart cities. J. Open Innov. Technol. Mark. Complex. 2016, 2, 8.

30. ENOLL: European Network of Living Labs 2010. 'Smart Cities' as Centres for User-Driven Open Innovation. Available online: http:/ / openlivinglabs.eu/news/\%E2\%80\%98smart-cities\%E2\%80\%99-centres-user-drivenopen-innovation (accessed on 16 July 2017).

31. Kitchin, R. Making sense of smart cities: Addressing present shortcomings. Camb. J. Reg. Econ. Soc. 2014, 8, 131-136. [CrossRef]

32. Komninos, N.; Bratsas, C.; Kakderi, C. Smart city ontologies: Improving the effectiveness of smart city applications. J. Smart Cities 2015, 1, 31-46. [CrossRef]

33. Paskaleva, K.; Cooper, I.; Linde, P.; Peterson, B.; Goetz, C. Smart city stakeholder engagement: Making living labs work. In Transforming City Governments for Successful Smart Cities; Bolívar, M., Ed.; Springer: Berlin, Germany, 2015; pp. 115-145.

34. Paskaleva, K.; Cooper, I. Co-production and governance for smart city services: Learning from practice: Introduction. Int. J. Serv. Technol. Manag. 2017, 1-12, in press.

35. Glasmeier, A.; Christopherson, S. Thinking about smart cities. Camb. J. Reg. Econ. Soc. 2015, 8, 3-12. [CrossRef]

36. Meijer, A.; Bolívar, M.P.R. Governing the smart city: A review of the literature on smart urban governance. Int. Rev. Adm. Sci. 2015, 82, 392-408. [CrossRef]

37. Scholl, H.J.; Barzilai-Nahon, K.; Ahn, J.; Olga, P.; Barbara, R. e-commerce and e-government: How do They Compare? What Can They Learn from Each Other? In Proceedings of the 42nd Hawaiian International Conference on System Sciences, Waikoloa, HI, USA, 5-8 January 2009.

38. Paskaleva, K. Smart cities: A nexus of open innovation? Intell. Build. Int. J. 2011, 3, 153-171. [CrossRef]

39. Odendaal, N. Information and communication technology and local governance: Understanding the difference between cities in developed and emerging economies. Comput. Environ. Urban Syst. 2003, 27, 585-607. [CrossRef]

40. Meijer, A.; Thaens, M. Urban technological innovation: Developing and testing a sociotechnical framework for studying smart city projects. Urban Aff. Rev. 2016. [CrossRef]

41. Kourtit, K.; Nijkamp, P.; Arribas, D. Smart cities in perspective-A comparative European study by means of self-organizing maps. Innov. Eur. J. Soc. Sci. Res. 2012, 25, 229-246. [CrossRef]

42. Innes, J.; Booher, D. The Impact of Collaborative Planning on Governance Capacity Working Paper 2003-03. Available online: https://www.econstor.eu/obitstream/10419/23606/1/WP-2003-03.pdf (accessed on 10 June 2017). 
43. Edelenbos, J.; Hirzalla, F.; van Zoonen, L.; van Dalen, J.; Bouma, G.; Slob, A.; Woestenburg, A. Governing the complexity of smart data cities: Setting a research agenda. In Smart Technologies for Smart Governments; Bolívar, M., Ed.; Springer: Berlin, Germany, 2017.

44. López-Quiles, J.; Rodríguez Bolívar, M. Smart technologies for smart governments: A review of technological tools in smart cities. In Smart Technologies for Smart Governments; Rodríguez Bolívar, M., Ed.; Springer: Berlin, Germany, 2017.

45. Morabito, V. Big Data and Analytics: Strategic and Organizational Impacts; Springer: Cham, Switzerland, 2015.

46. Bakıcı, T.; Almirall, E.; Wareham, J. A smart city initiative: The case of Barcelona. J. Knowl. Econ. 2012, 4, 135-148. [CrossRef]

47. Van Winden, W.; van den Buuse, D. Smart city pilot projects: Exploring the dimensions and conditions of scaling up. J. Urban Technol. 2017, 24, 51-72. [CrossRef]

48. Gurstein, M. Open data: Empowering the empowered or effective data use for everyone? First Monday 2011, 16. [CrossRef]

49. Allerin. Smart Cities Need Open Data Governance. Available online: https://www.allerin.com/blog/smartcities-need-open-data-governance (accessed on 7 June 2017).

50. Lee, J.; Hancock, M.; Hu, M.-C. Towards an effective framework for building smart cities: Lessons from Seoul and San Francisco. Technol. Forecast. Soc. Chang. 2014, 89, 80-99. [CrossRef]

51. Yin, R. Case Study Research: Design and Methods, 5th ed.; Sage Publications: Thousand Oaks, CA, USA, 2014.

52. McCusker, K.; Gunaydin, S. Research using qualitative, quantitative or mixed methods and choice based on the research. Perfusio 2015, 30, 537-542. [CrossRef] [PubMed]

53. Bryman, A.; Emma, B. Business Research Methods, 4th ed.; Oxford University Press: Oxford, UK, 2015.

54. Evans, J.; Blakey, J.; Karvonen, A.; Paskaleva, K.; Wiktorski, T.; Yang, J. Smart City Monitoring and Impact Assessment Framework, Triangulum Project Report (Deliverable 2, 1). Available upon request from authors. 2015.

55. Weill, P.; Ross, J. IT Governance: How Top Performers Manage IT Decision Rights for Superior Results; Harvard Business School Press: Boston, MA, USA, 2004.

56. Kharti, V.; Brown, C. Designing data governance. Commun. ACM 2010, 53, 148-152.

57. Office of the Deputy Prime Minister: London the Principles of Good Data Management. 2005. Available online: https:/ / www.gov.uk/government/uploads/system/uploads/attachment_data/file/14867/Good_ dataMan.pdf (accessed on 13 September 2017). 